\title{
ПРИМЕНЕНИЕ МОДЕЛЬНЫХ РЕАКЦИИ ДЛЯ ОЦЕНКИ ВОЗДЕИСТВИЯ ЭЛЕКТРИЧЕСКОГО РАЗРЯДА НА ЖИЛКОСТЬ 1. ДЕГРАДАЦИЯ 3,4-БЕНЗПИРЕНА В ВОДНОМ РАСТВОРЕ ПРИ РАЗРЯДЕ НА ГРАНИЦЕ РАЗДЕЛА ФАЗ
}

B. BRODSKAJA, LII PAALME, M. GUBERGRITS. MUDELREAKTSIOONIDE KASUTAMINE ELEKTRILAHENDUSE TOIME HINDAMISEKS LAHUSELE. 1. 3,4-BENSOPUREENI DEGRADATSIOON VESILAHUSE JA OHU PUUTEPINNAL TOIMUVA ELEKTRILAHENDUSE KORRAL

B. BRODSKAYA, Lia PAALME, M. GUBERGRITS. EVALUATION OF THE EFFECT OF ELECTRICAL DISCHARGE BY THE USE OF MODEL REACTIONS IN LIQUID PHASE. 1. THE DEGRADATION OF 3,4-BENZOPYRENE UNDER THE DISCHARGE ON THE LIQUID AND GAS PHASE BOUNDARY

В сообщении ['] показана возможность применения для оценки воздействия электрического разряда на жидкость наряду с известной дозиметрической системой Фрике некоторых модельных реакций. K ним относится, в частности, окислительная деградация 3,4-бензпирена (БП).

Ниже приведены основные результаты исследования с применением указанной реакции в системе БП-вода, обусловленной разрядом на поверхности раздела контактирующих жидкой и газовой (воздух) фаз. В работе использован выполненный из оргстекла герметичный реактор, в котором заполняемый жидкостью объем составляет 500 мл. Схема установки и методика электрофизических измерений описаны ранее [2], как и сущность физических явлений, протекающих при подобной организации разряда [3]. В опытах применено напряжение $15 \kappa 8$ и емкость в ударе 0,6 мкф.

Электрофизическая характеристика разряда, организованного на поверхности водного раствора БП либо ферросульфатного дозиметрического раствора, который имеет периодический характер с декрементом затухания 0,3 и 0,35 при равной длительности 140 мксек, дана на рис. 1 . Различия в амплитудных значениях тока и интенсивности свечения обусловлены разной проводимостью растворов - 0,01 и $13,5 \mathrm{cus} / \mu$. Хотя для раствора Фрике характерно значительное выделение энергии в предпробивном периоде, тем не менее при определении дозы подведенной энергии данные обеих систем сопоставимы.

Состав реакционной смеси определяется путем ее разделения после экстрагирования бензолом в тонком слое окиси алюминия и съемки квазилинейчатых спектров флуоресценции по модифицированной нами методике [ $\left.{ }^{4}\right]$ с погрешностью не более $5 \%$.

Основные результаты кинетического исследования приведены в таблице и на рис. 2. Суммарный процесс деградации БП в водном растворе описывается кинетическим уравнением реакции второго порядка, константа скорости которого составляет $3,3 \cdot 10^{4}$ л/моль сек. Средняя скорость превращения БП на основном отрезке достигает $1,2 \cdot 10^{-6}$ моль $/ \Omega \cdot 4$ при энергетическом выходе деградации в $6 \cdot 10^{-5}$ молек/10 әв. Фактический выход превращенного БП в расчете на поглощенную дозу энергии по дозиметру Фрике оказывается выше примерно на один порядок вели- 


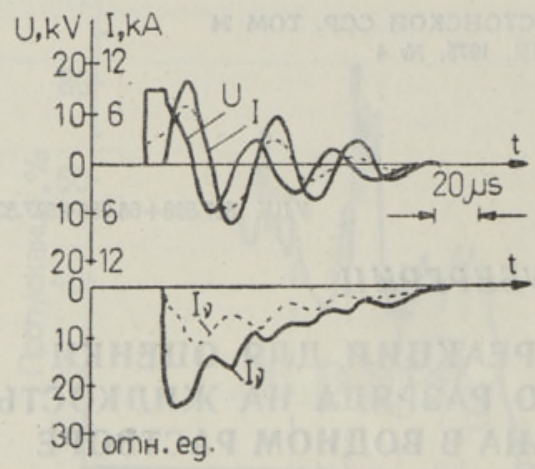

Рис. 1. Осциллограммы тока и напряжения и интенсивность свечения в центре межэлектродного промежутка при разряде на поверхности водного раствора 3,4-бензпирена (сплошные линии) и ферросульфатного дозиметрического раствора (пунктирные линии).

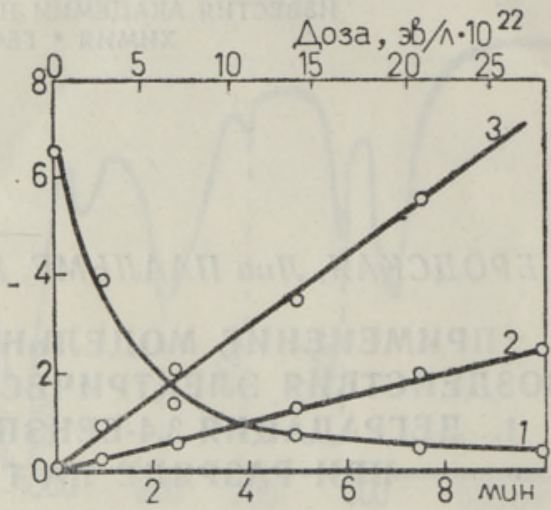

Рис. 2. Кинетическая кривая деграда-

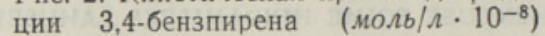
(1), графическая проверка порядка реакции $\left(\Lambda \cdot \mu^{-1} \cdot 10^{7}\right)$ (2) и образование перекиси водорода (молек/ $\Omega$. $\left.\cdot 10^{22}\right)(3)$

Кинетическая характеристика процесса окислительной деградации 3,4-бензпирена в водном растворе под действием скользящего разряда

\begin{tabular}{|c|c|c|c|c|c|c|}
\hline \multirow[b]{2}{*}{ Показатели } & \multicolumn{6}{|c|}{ Число разрядов } \\
\hline & 0 & 10 & 25 & 50 & 75 & 100 \\
\hline 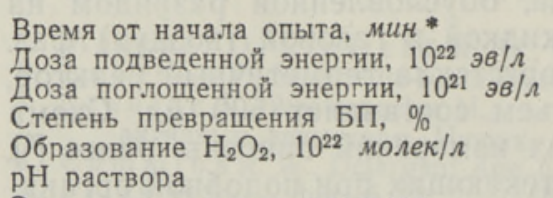 & 6,25 & $\begin{array}{c}1 \\
2,8 \\
2,1 \\
39,4 \\
0,92 \\
3,40\end{array}$ & $\begin{array}{c}2,5 \\
7,0 \\
5,1 \\
80 \\
2,16 \\
3,35\end{array}$ & $\begin{array}{r}5 \\
14,0 \\
8,7 \\
86,0 \\
3,5 \\
2,9\end{array}$ & $\begin{array}{r}7,5 \\
21,0 \\
13,3 \\
91,0 \\
5,65 \\
2,85\end{array}$ & $\begin{array}{l}10 \\
28,0 \\
15,0 \\
94,0 \\
2,80\end{array}$ \\
\hline $\begin{array}{l}\text { Электропроводность раствора, } \\
10^{-4} \text { обр. ом. }\end{array}$ & 0,1 & 1,7 & 2,5 & 5,1 & 7,0 & 10,5 \\
\hline $\begin{array}{l}\text { Энергетический выход деградации } \\
\text { БП, } 10^{-5} \text { молек/100 эв } \\
\text { Фактический выход деградации, в }\end{array}$ & & 5,8 & 4,1 & 2,5 & 1,7 & 1,4 \\
\hline $\begin{array}{l}\text { Фактический выход деградации, в } \\
\text { расчете на поглощенную энергию, } \\
10^{-4} \text { молек/100 эв }\end{array}$ & & 7,4 & 6,2 & 3,9 & 2,7 & 2,5 \\
\hline
\end{tabular}

* Интервал между разрядами около 6 сек.

чин. В числе продуктов превращения БП идентифицирована смесь 5,8- и 5,10 -хинонов, как известно, не обладающих канцерогенными свойствами. Часть продуктов нерастворима в воде и осаждается на стенках реактора. Средняя скорость $\left(V_{\mathrm{cp}}\right)$ деградации БП сопоставима с показателями для воздействия на водные растворы БП других энергоносителей при учете различий в его концентрации $(C)$.
$C$
$V_{\text {op }}$
моль/л
моль/ $/ \Omega \cdot 4$
Энергоноситель
Источник

$\begin{array}{crl}6,5 \cdot 10^{-8} & 1,2 \cdot 10^{-6} & \text { Скользящий разряд } \\ 7,3 \cdot 10^{-11} & 1,74 \cdot 10^{-9} & \text { УФ-излучение } \\ 4 \cdot 10^{-7} & 2,1 \cdot 10^{-6} & \begin{array}{l}\text { Биодеградация на актив- } \\ \text { ных илах }\end{array}\end{array}$

Настоящее исследование 


\section{Л И ТЕ РА Т У Р А}

1. Бродская Б., Ки рсо У., П а льме Л., Изв. АН ЭССР. Хим. Геол., в печати.

2. Бродская Б., ЭОМ, № 1 (1971).

3. Бродск а Б., Т рапи до Г., Изв. АН ЭССР. Физ.-матем., 23, № 3 (1974).

4. Федосее в а Г. Е., Хесина А. Я., Ж. прикладной спектроскопии, IX, вып. 2, 282 (1968).

5. Гу бергриц $M_{t}$, Па альме Л., Изв. АН ЭССР. Хим. Геол., 23, 283 (1974).

6 . Ханнус М., Ки исо У., Губерг иц М., Изв. АН ЭССР. Хим. Геол., 24,240 (1975).

Институт химии
Академии наук Эстонской ССР

EESTI NSV TEADUSTE AKADEEMIA TOIMETISED. 24. KOIDE KEEMIA * GEOLOOGIA. 1975, NR. 4

ИЗВЕСТИЯ АКАДЕМИИ НАУК ЭСТОНСКОИ ССР. ТОМ 24 ХИМИЯ • ГЕОЛОГИЯ. 1975 , № 4

К. ЛЭЭТС, Т. КААЛ, А. ЛИНДСААР

Поступила в редакцию

$14 / 1 \quad 1975$

\section{МЕТИЛИРОВАННЫЕ ТЕРПЕНОВЫЕ СПИРТЫ ИЗ ТЕЛОМЕРА ИЗОПРЕНА С ГИДРОХЛОРИДОМ ДИМЕТИЛБУТАДИЕНА}

K. LAATS, T. KAAL, A. LINDSAAR. ISOPREENI JA DIMETOULBUTADIEENI HODROKLORIIDI TELOMEERIST SAADUD METOOLITUD TERPEENALKOHOLID

K. LAATS, T. KAAL, A, LINDSAAR. METHYLSUBSTITUTED TERPENIC ALCOHOLS FROM THE TELOMER OF ISOPRENE WITH THE HYDROCHLORIDE OF DIMETHYLBUTADIENE

О теломеризации изопрена с гидрохлоридом диметилбутадиена сообщалось ранее [1]. Из фракции теломера $\mathrm{C}_{11}$ при помощи реакции Соммле селективно был выделен основной продукт - 6-метилгеранилхлорид и превращен в метилцитраль, из которого далее был получен ирон (ценное душистое вещество).

В настоящей работе исследован продукт омыления изомерных хлоридов $\mathrm{C}_{11} \mathrm{H}_{19} \mathrm{Cl}$, не вступающих в реакцию с гексаметилентетрамином. Образующиеся при этом спирты могут представить интерес для парфюмерии.

Аналогично продукту, полученному из теломера изопрена с его гидрохлоридом [2], по данным ГЖХ из изомерных хлоридов $\mathrm{C}_{11} \mathrm{H}_{19} \mathrm{Cl}$ образовался ряд изомерных спиртов. Из них разгонкой были выделены два компонента, которые по данным ЯМР- и ИК-спектроскопии представляют собой 3, 6, 7-триметил-1,6-октадиен-3-ол (6-метиллиналоол) и 1,4-диметил-4-гидроксиизопропил-1-циклогексен (4-метил- $\alpha$-терпинеол). Эти спирты образуются из продуктов присоединения гидрохлорида диметилбутадиена к изопрену соответственно в положениях 1,2 и 1,4 с последующей циклизацией. Продукт 4,3-присоединения, полученный с гидрохлоридом изопрена $\left.{ }^{2}\right]$, в настоящей работе выделить не удалось.

Метиллиналоол получен ранее $\left.{ }^{3}, 4\right]$ селективным гидрированием $3,6,7$, триметил-6-октен-1-ин-3-ола. Метилтерпинеол в литературе не описан.

150 г (0,8 моля) изомерных хлоридов $\mathrm{C}_{11} \mathrm{H}_{19} \mathrm{Cl}$, оставшихся после выделения из смеси первичного аллильного хлорида в виде комплекса с гексаметилентетрамином [1], в течение 5 ч омыляли в кипящем водно- 